\title{
Joining of tubular steel-steel by unconventional magnetic pulse force: environmentally friendly technology
}

\author{
K SHANTHALA $^{1, *}$, T N SREENIVASA $^{1}$, H N NARASIMHA MURTHY $^{2}$, SHANTHARAM DOND $^{3}$, \\ HITESH CHOUDHURY ${ }^{3}$ and ARCHANA SHARMA ${ }^{3}$ \\ ${ }^{1}$ AMC Engineering College, Visvesvaraya Technological University, Bengaluru 560083, India \\ ${ }^{2} \mathrm{R}$ V College of Engineering, Bengaluru 560059, India \\ ${ }^{3}$ Bhabha Atomic Research Centre, Mumbai 400085, India \\ *Author for correspondence (kshanthala2@gmail.com)
}

MS received 19 October 2018; accepted 8 March 2019

\begin{abstract}
Electromagnetic welding uses environment-friendly, unconventional non-contacting magnetic pulse force for joining of two metals. The present paper focuses on the welding of tubular mild steel to two different steel bars, ferrite-pearlite 1018 carbon steel and austenite 304 stainless steel using a $40 \mathrm{~kJ}$ electromagnetic instrument. A qualitative metallurgical bonding was obtained for a selected set of optimum process parameters. The bonded region did not show localized melting for a mild steel-carbon steel joint and was found to be homogeneous liquid state bonding for a mild steel-stainless steel joint within a restricted distance of $3 \mu \mathrm{m}$ from the interface. Both the joints indicated good peel strength and leak tightness. Simulation studies were validated using experimental parameters such as voltage, current, impact velocity, magnetic flux and displacement.
\end{abstract}

Keywords. Carbon steel; stainless steel; electromagnetic; joining; welding.

\section{Introduction}

Welding of steel is always associated with a detrimental heat affected zone due to the high-melting temperature of steel. Electromagnetic welding (EMW) has demonstrated strong metallurgical bonding between a wide range of metals of a high-melting point without any heat affected zone [1,2]. EMW can be treated as environment-friendly technology which uses non-contacting electromagnetic pulse force for joining. EMW is a type of solid state impact welding analogous to the explosive welding (EXW). Unlike an EXW, which uses harmful chemical explosives or additional filler metals in conventional welding, in EMW, electromagnetic Lorenz force (magnetic pulse force) accelerates one of the constituent materials known as flyer onto a target material, causing collision between the two materials and resulting in joining. Joining takes place under high-impact force within few microseconds in the velocity range of $300-500 \mathrm{~ms}^{-1}$ [3].

Extensive research is reported on EMW of lightweight aluminium and highly conductive copper as flyers joined to target materials such as aluminium [4], copper [4,5], steel [2,6], magnesium [7], titanium and brass [4,8] either for the lap configuration of sheets or for tubular structures. The literature indicated the presence of waviness and related severe plastic deformation at the weld line. A metallurgical bond was also observed at the interface with a thin layer of intermetallics which were reported to have limited or no influence on the mechanical strength of the joint.
As the focus is mainly on lightweight flyer materials, very limited information is available on EMW of steel to steel. Stern and Aizenshtein [9] reported EMW of the ferritic steel tubular structure. They reported the formation of a fine grained melt layer with higher hardness at the interface. However, this report has no reference to process parameters and does not mention the geometrical parameters of the flyer and target. The microstructure of the interface is not clearly detailed and mechanical strength of the joint is not predicted. Ghosh et al [10] reported EMW of plain carbon steel sheets. They reported the formation of distinct zones of both the solid state and liquid state along the weld length. For a flyer-target with a length of $200 \mathrm{~mm}$, the weld length is reported at $1 \mathrm{~mm}$ which is very insignificant. A larger weld interface was observed in the presence of micro-pores and micro-cracks and is not in correlation with the sample length for tensile strength. Some of the open literature studies reported joining of a steel flyer to steel target, both the plate and tubular configuration by EXW [11-13]. In summary, EXW reported the presence of both the flat and wavy morphology with an occasional melt zone in accordance with the explosive loading. There are no references on the strength of weld joints.

Practically, joining of steel with sound quality is not very well established in the open literature. The reported literature on simulation of EMW of steel is very scarce. Simulation data are especially useful in selecting the complex process parameters of EMW experiment. In this study, sound quality joint is obtained between the mild steel flyer and steel targets of 
different structures, namely, ferrite-pearlite 1018 carbon steel and austenite 304 stainless steel. Simulation studies have been validated using the actual experimental parameters: voltage, current, impact velocity, magnetic flux and displacement.

\section{Experimental}

\subsection{Welding setup and materials}

In this work, joining experiment was carried out using an indigenously built electromagnetic instrument $(40 \mathrm{~kJ} / 20 \mathrm{kV})$ with parallel capacitor banks, spark gap switch, coils and arrangements to hold the target-flyer work piece. A schematic diagram of the setup and electromagnetic coil set used for the experiment is shown in figure 1. The tool used for welding was a bitter compression type electromagnetic coil of 3.3 turn made of copper-beryllium (figure 2).

Geometrical parameters (figure 3) were selected based on the coil design and commercial requirements. Materials used were flyers made out of mild steel with an outer diameter of $46 \mathrm{~mm} / \mathrm{a}$ thickness of $0.5 \mathrm{~mm}$ and two different steel targets, namely, 1018 carbon steel and 304 stainless steel with an outer diameter of $43 \mathrm{~mm}$. The stand-off distance was maintained at $1.5 \mathrm{~mm}$ with an impact angle of $5^{\circ}$. Due to the low conductivity of steel, aluminium drivers of $0.7 \mathrm{~mm}$ were lapped over

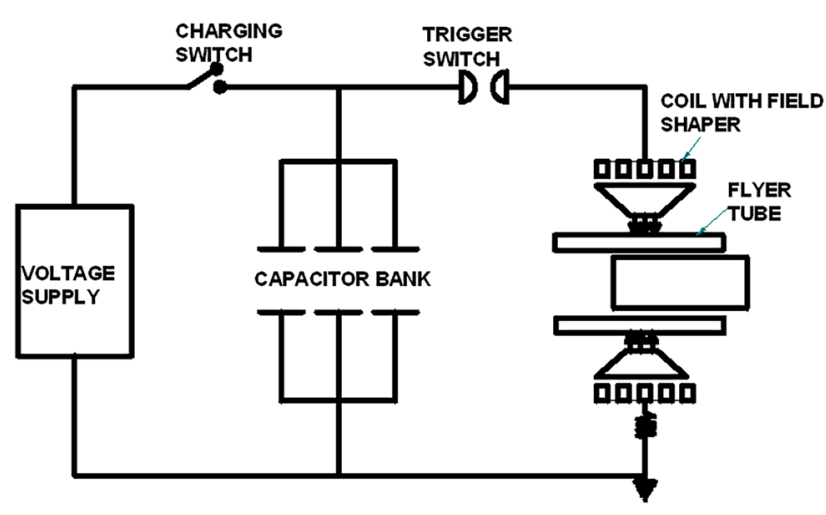

Figure 1. Schematic diagram of the EMW setup [1].

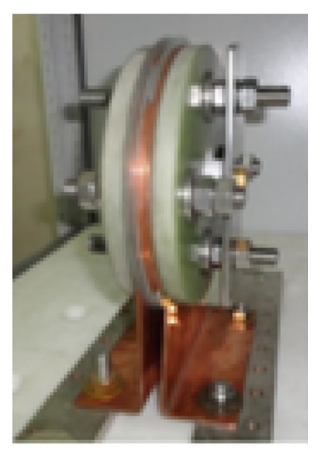

Figure 2. EM coil [14].

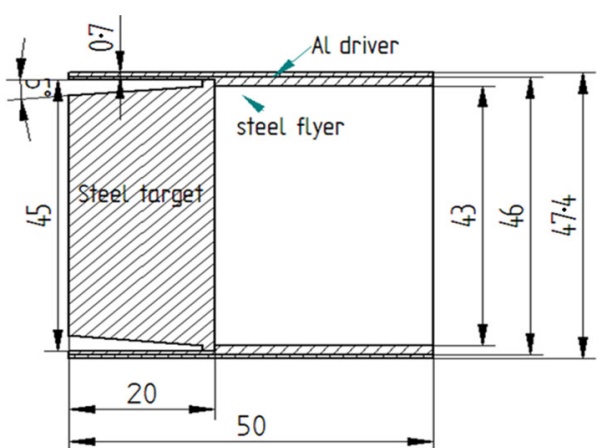

Figure 3. Geometrical details.

the flyer tube. The setup was charged to a voltage of $17 \mathrm{kV}$ at a frequency of $10 \mathrm{kHz}$ for both the targets. Damped discharge current delivered to electromagnetic coil was recorded by using an oscilloscope. The samples were prepared for the purpose of micro-examination from the cut sections of the welded area.

\subsection{Characterization of welded samples}

Micro-examination of the joint interface was evaluated by using an AxioVert, Zeiss optical microscope, with an image analyser Clemex Vision PE. A field emission type scanning electron microscope (SEM) (Carl Zeiss model) attached with energy dispersive spectroscopy (EDS) (Oxford X-Act model) was used for both microstructure evaluation and compositional analysis. A transmission electron microscope (TEM) (Titan G2 60-300 FEI model) was used for the evaluation of the interface of mild steel-1018 carbon steel. Microhardness evaluation was carried out across the joint interfaces, by a standard ASTM E384-16 test method, using a MatsuzawaMMTX7 hardness tester, with a load of $100 \mathrm{~g}$ and a dwell time of $10 \mathrm{~s}$. The joint tightness was tested using a VS Series Agilent helium leak detector with a sensitivity of $10^{-12}$ torr$1 / \mathrm{s}$. Helium was sprayed on one side of the joint after creating a vacuum level of $5.9 \times 10^{-9}$ torr-1/s. A trace of helium sensed on the other side of the joint by the leak detector was taken as a measure for tightness of the joint. The mechanical strength of the joint was evaluated by peeling the sample using a wedge tool in a UTM of capacity $400 \mathrm{kN}$ at a rate of $1 \mathrm{~mm} \mathrm{~min}^{-1}$. The force needed to separate the interface was recorded.

\section{Results and discussion}

\subsection{Experimental studies}

The photographs of the flyer and the target pieces before and after welding are shown in figure 4. Peak experimental current was found to be at $195 \mathrm{kA}$. Magnetic flux corresponding to the discharging current was $15 \mathrm{~T}$, at the driver surface. The helium leak test indicated a leakage rate of $10^{-8}$ torr-1/s confirming 

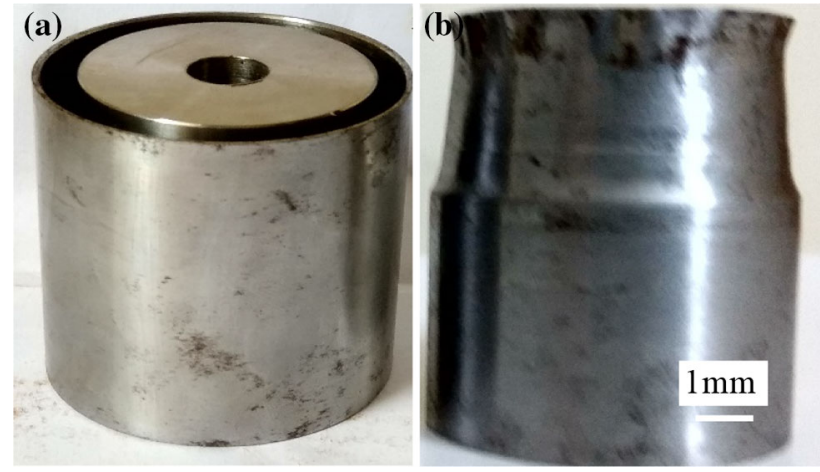

Figure 4. Flyer and target (a) before welding and (b) after welding.

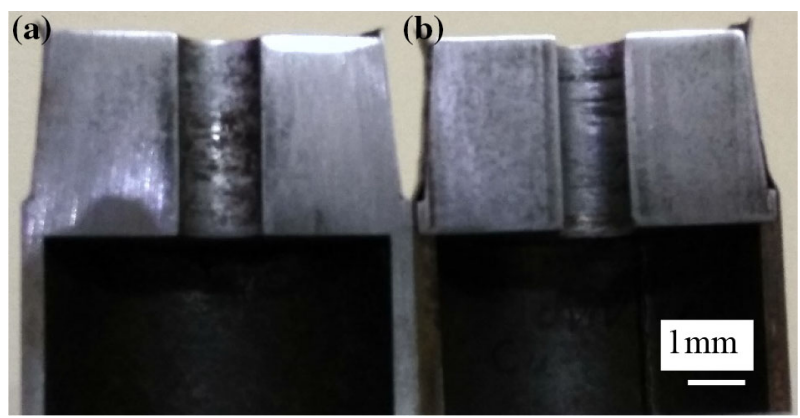

Figure 5. Cut section of (a) mild steel-stainless steel and (b) mild steel-1018 carbon steel.

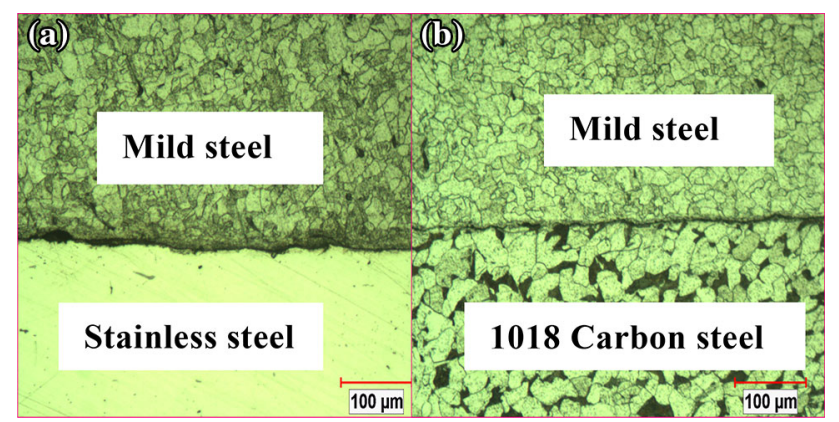

Figure 6. Interface microstructure of (a) mild steel-stainless steel and (b) mild steel-1018 carbon steel.

the integrity of the welded joint for both the samples. Visual inspection of the cut section (figure 5) indicated good bonding between the flyer and the target for both types of steel targets with a weld length of $16 \mathrm{~mm}$.

Optical microscopy images (figure 6) indicated a structure of the base metal under the etched condition for the mild steel flyer having fine pearlite in the ferrite matrix, 1018 carbon steel having pearlite in the ferrite matrix and stainless steel with the austenite structure under the unetched condition. Clear bonding of the flyer with the target was observed in both the samples with a wavy morphology at the interface, though, the wavy morphology was more clearly observed in the mild steel-1018 carbon steel sample. Further

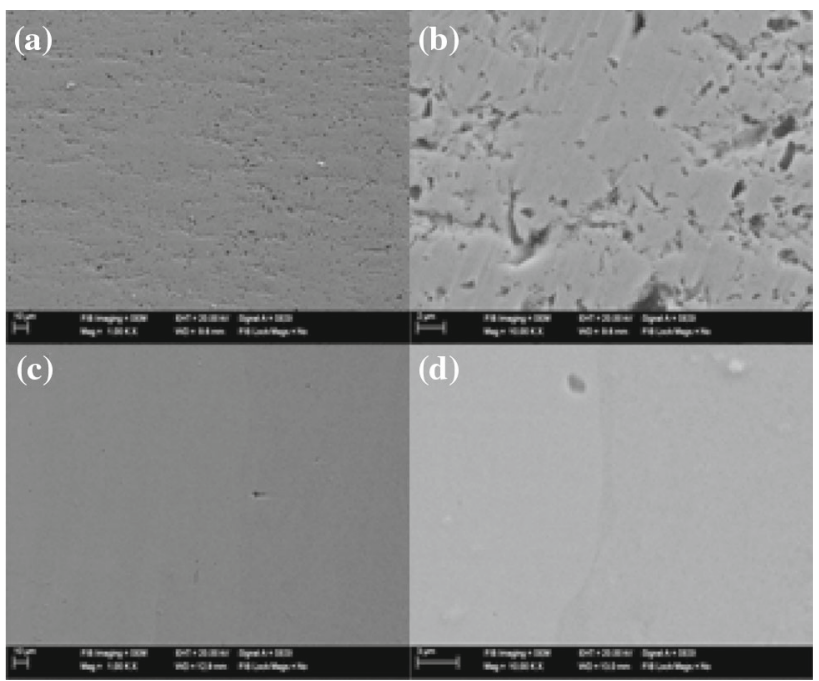

Figure 7. SEM images of (a and b) mild steel-1018 carbon steel and (c and d) mild steel-stainless steel.

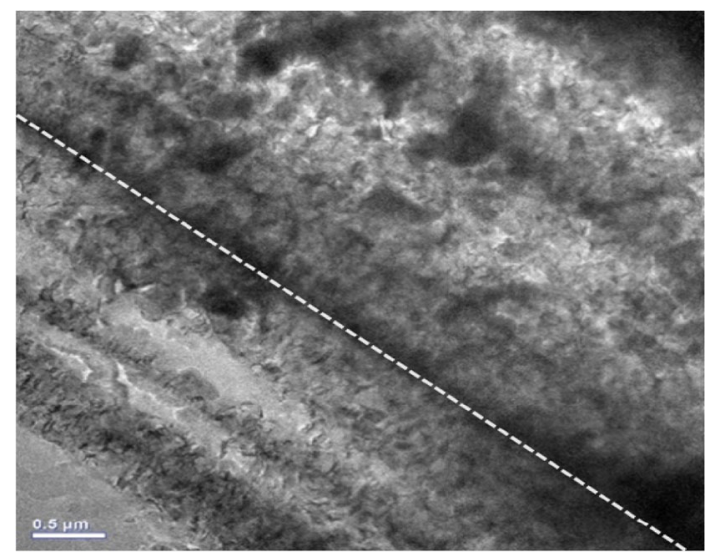

Figure 8. TEM image at the interface of mild steel-1018 carbon steel.

examination of the sample under SEM (figure 7) indicated a complete merger of the interface for both the steel targets. The mild steel-1018 carbon steel joint was observed with pittings and the demarcation of the interface was difficult as can be seen in figure $7 \mathrm{a}$ and $\mathrm{b}$. The mild steel-stainless steel joint was observed with a clear interface with a thin melt zone of $3 \mu \mathrm{m}$ in figure $7 \mathrm{c}$ and $\mathrm{d}$. The TEM image (figure 8 ) at the interface of the mild steel-1018 carbon steel joint was observed with severe plastic deformation with twinning. Selected area electron diffraction (SAED) indicated the presence of $\alpha^{\prime}$ martensite and nanograins (figure 9) at the interface. From the above observations it can be pointed out that in ferrite-pearlite steel EMW is established by severe plastic deformation and mechanical interlocking, forming a pure solid state bonding. The presence of $\alpha^{\prime}$-martensite indicated stress-induced phase transformation and nanograins are typical features of EMW. Pitting near the interface is attributed to the diffusion of carbon near the interface. 


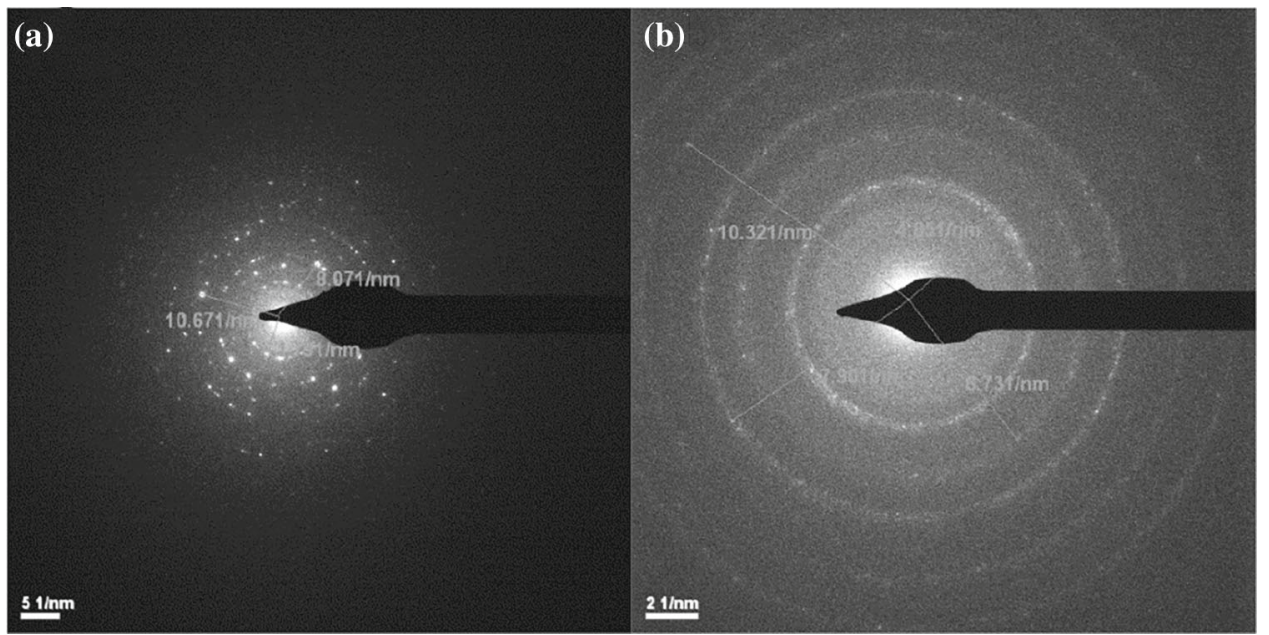

Figure 9. SAED pattern at the interface of mild steel-1018 carbon steel: (a) martensite phase and (b) amorphous phase.

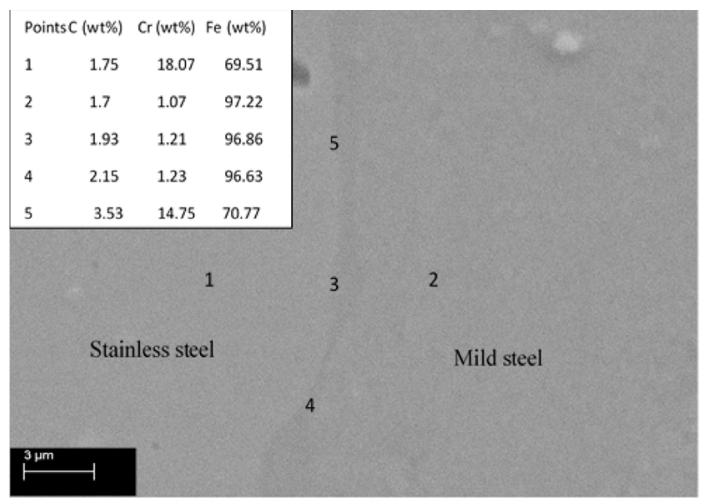

Figure 10. Chemical composition record of the EDS-spectrum at different points of mild steel-stainless steel.

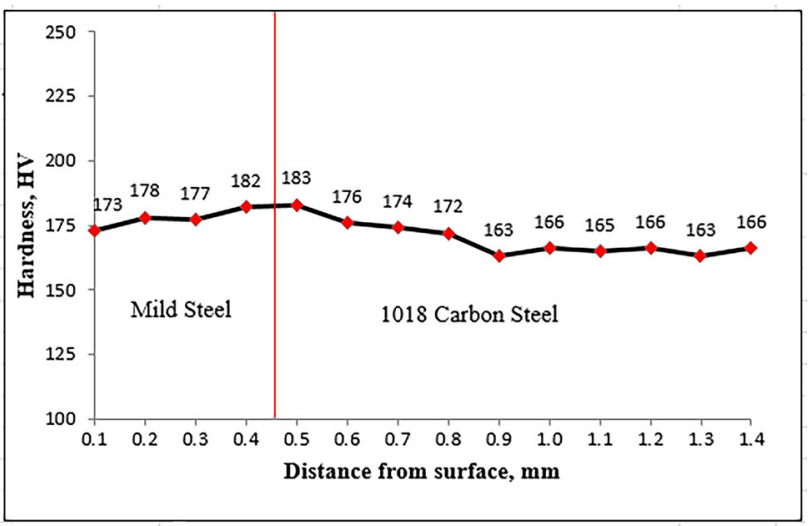

Figure 11. Microhardness profile of mild steel-1018 carbon steel.

Chemical composition for the major elements recorded from the EDS-spectrum for mild steel-stainless steel is shown in figure 10 . There was no variation in the chemical composition of the base metal on both stainless steel and mild steel sides (points 1 and 2 in figure 10). At point 5 , on the stainless steel side, $14.75 \mathrm{wt} \%$ of chromium $(\mathrm{Cr})$ was noted as against $18 \mathrm{wt} \%$ in the base stainless steel. At two other points, 3 and 4, along the interface, the compositions were slightly $\mathrm{Cr}$ rich. A slight variation in the carbon distribution was also observed at points 4 and 5. In comparison with the mild steel-1018 carbon steel joint, there was no pitting visible at the interface of the mild steelstainless steel joint. Chromium diffusion on the mild steel side does not seem to have any effect on the corrosion at the interface of the mild steel-stainless steel joint. Elemental diffusion is attributed to the rise in the temperature at the interface during the joining process, indicating that EMW in the mild steel-stainless steel joint taking place by liquid state welding.

In summary, in a ferrite-pearlite structure, joining takes place by severe plastic deformation under the solid state, attributed to rapid dissipation of heat associated with high-thermal conductivity of 1018 carbon steel. In the ferriteaustenitic structure joining is assumed to takes place under the liquid state, attributed to slow dissipation of heat because of low-thermal conductivity of stainless steel.

Microhardness profiles indicated no change in the hardness of the base metals on either side of the interface for both the samples (figures 11 and 12). Microhardness was slightly higher with a maximum hardness of $183 \mathrm{HV}$ near the interface when compared to the hardness of 173 and $163 \mathrm{HV}$ for base mild steel and 1018 carbon steel, respectively (figure 11). An increase in the hardness at the interface indicated plastic deformation for a larger distance of $0.4 \mathrm{~mm}$ on either side of the interface. Plastic deformation was confirmed by the TEM images, which were pointing to the deformation by twinning at the interface. Microhardness was higher by 30 $\mathrm{HV}$ at the interface of the mild steel-stainless steel joint. An increase in the hardness at the interface was justified by the formation of zone and possible precipitation of chromium carbide (figure 12). 


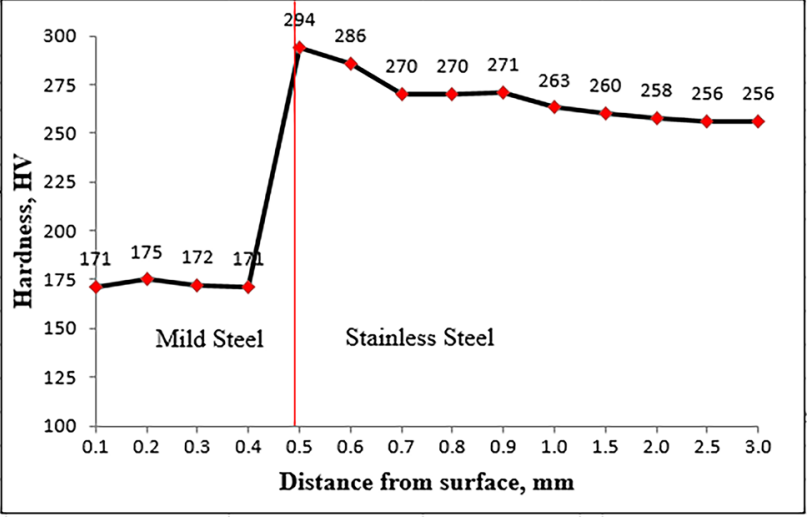

Figure 12. Microhardness profile of mild steel-stainless steel.

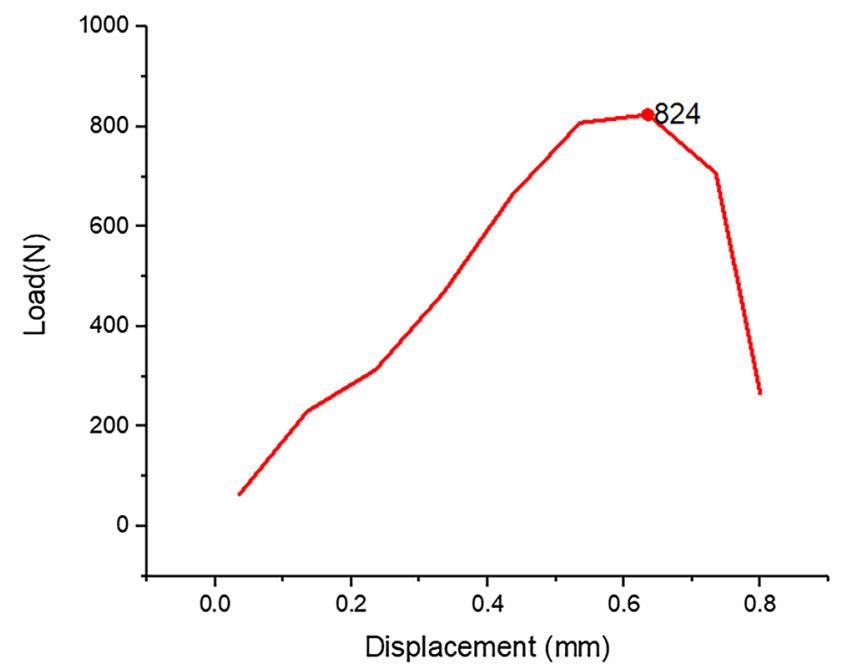

Figure 13. Load-displacement curve for peel strength of the mild steel-stainless steel joint.

Load-displacement curves related to the peel strength for samples mild steel-1018 carbon steel and mild steel-stainless steel are presented in figures 13 and 14. Peel strength was recorded at $1178 \mathrm{~N} \mathrm{~mm}^{-1}$ for the mild steel-stainless steel sample. Peel strength was recorded at $416 \mathrm{~N} \mathrm{~mm}^{-1}$ for mild steel-1018 carbon steel. Lower peel strength for mild steel1018 carbon steel was attributed to the pitting and carbon diffusion at the interface.

\subsection{Simulation studies}

A two-dimensional (2D) axisymmetric model for mild steel-stainless steel EMW with the assistance of aluminium driver was simulated and analysed in COMSOL, a multi physics software. Geometrical parameters from the experimental studies were used in the simulation. Half of the axisymmetric model was used for simulation. Analysis was carried out at various points on the outer surface of the flyer tube along the length of coil marked as 1,2 and 3 in figure 15 .

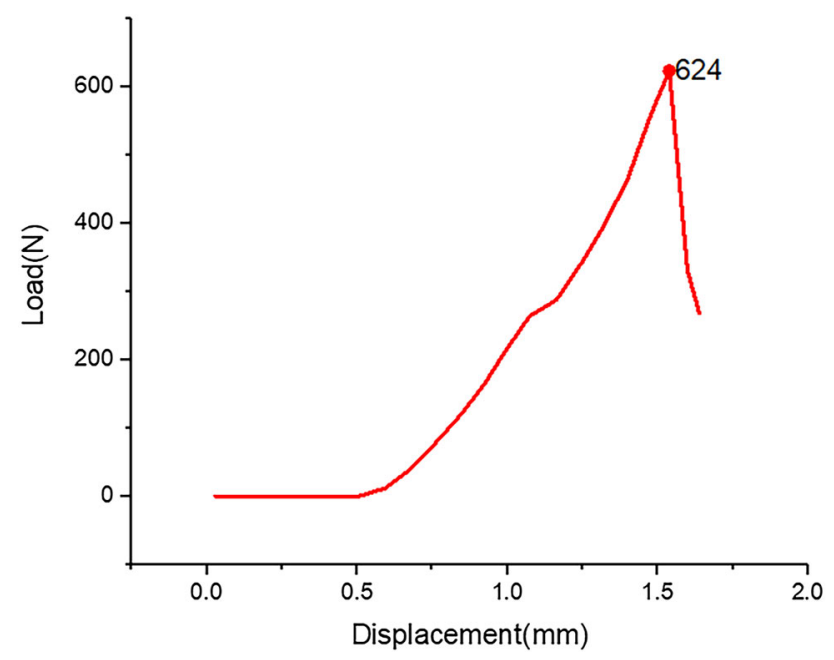

Figure 14. Load-displacement curve for peel strength of the mild steel-1018 carbon steel joint.

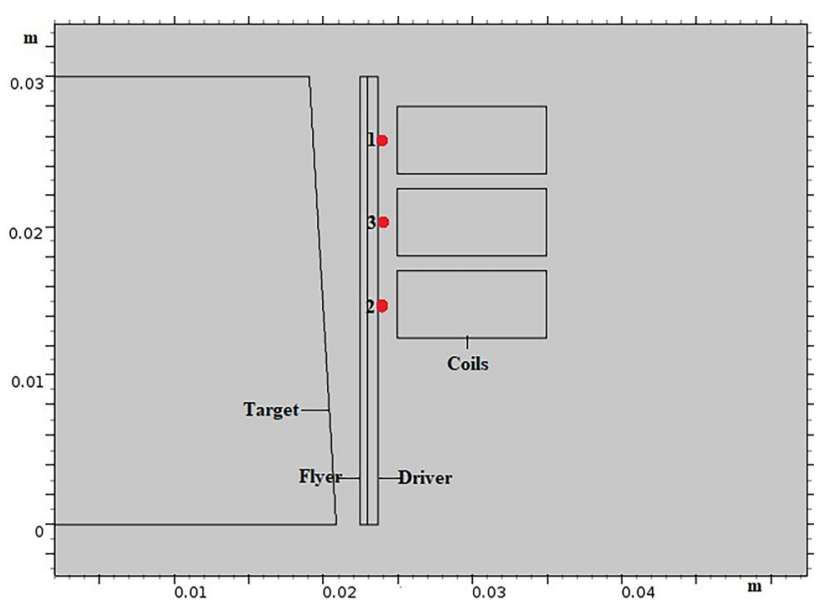

Figure 15. Driver-assisted 2D axisymmetric model (flyer surface marked 1,2 and 3).

The input voltage was taken at $17 \mathrm{kV}$ and current at $190 \mathrm{kA}$ with a peak time of $20 \mu \mathrm{s}$ for which the samples were welded successfully in the experiment. Related governing equations and boundary conditions are explained elsewhere [3] by the same authors.

The time-dependent impact velocity plot in figure 16 at three different points along the flyer surface indicated that velocity is not constant. This is in complete agreement with the tapering geometry of the target and variation of the standoff distance. Velocity at point 1 , the free end of the coil, was maximum with $360 \mathrm{~m} \mathrm{~s}^{-1}$. Welded samples were observed with rebounding of the flyer at the free end. The free end of the flyer was open without being welded to the target. This is attributed to the edge effect [3] associated with the magnetic field and justifying the high-impact velocity causing the rebounding of the flyer tube. The middle region of the coil at point 3 indicated an impact velocity of $324 \mathrm{~m} \mathrm{~s}^{-1}$ and the coil region with a low-stand-off distance was found 

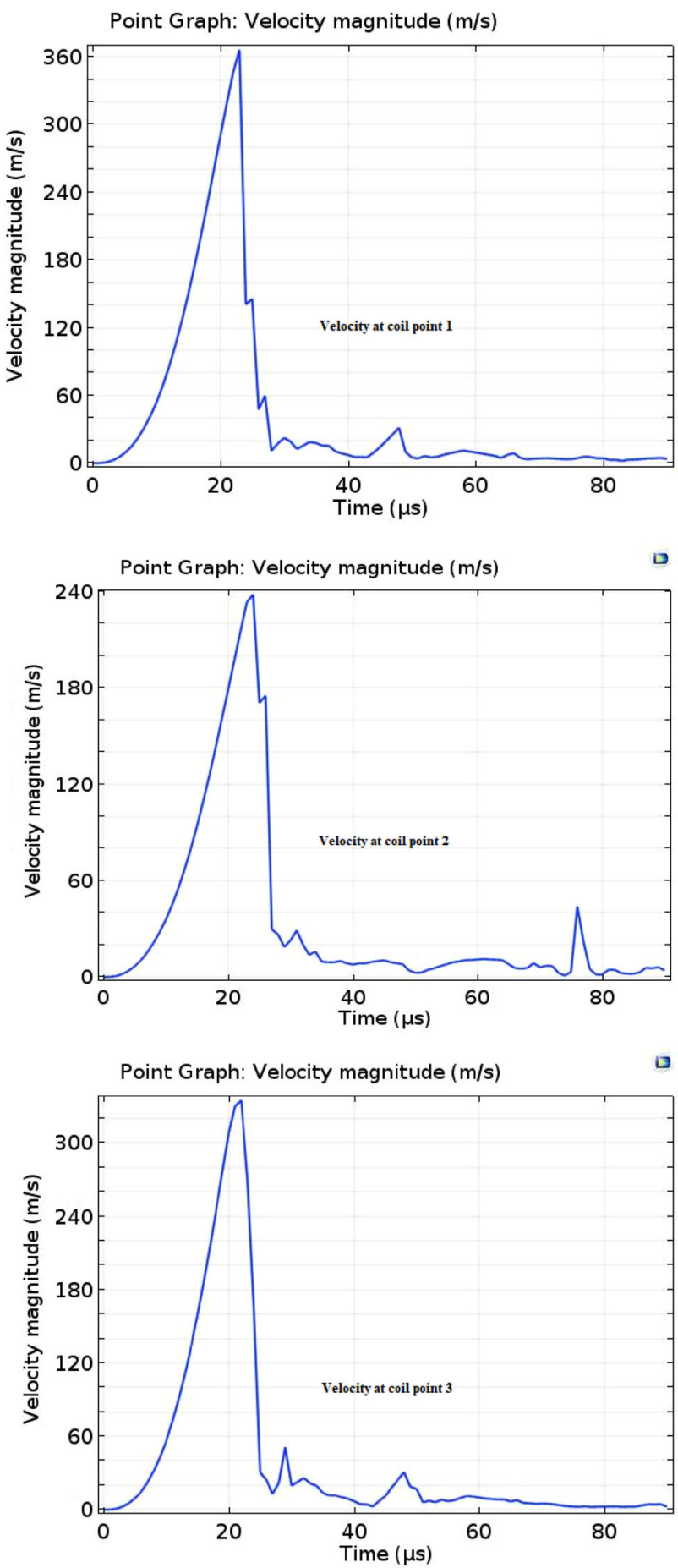

Figure 16. Time-dependent impact velocity plot (at points 1,2 and 3 on the flyer surface).

to have an impact velocity of $240 \mathrm{~m} \mathrm{~s}^{-1}$. The average velocity, $306 \mathrm{~m} \mathrm{~s}^{-1}$, is in agreement with the minimum theoretical impact velocity of $300 \mathrm{~m} \mathrm{~s}^{-1}$ [3]. The peak impact velocity of the flyer was found to be at $25 \mu$ s following the peak rise time of input current of $20 \mu \mathrm{s}$. Further the impact velocity is almost zero in figure 16, indicating that the flyer and target stand-off distance is zero, establishing the impact.

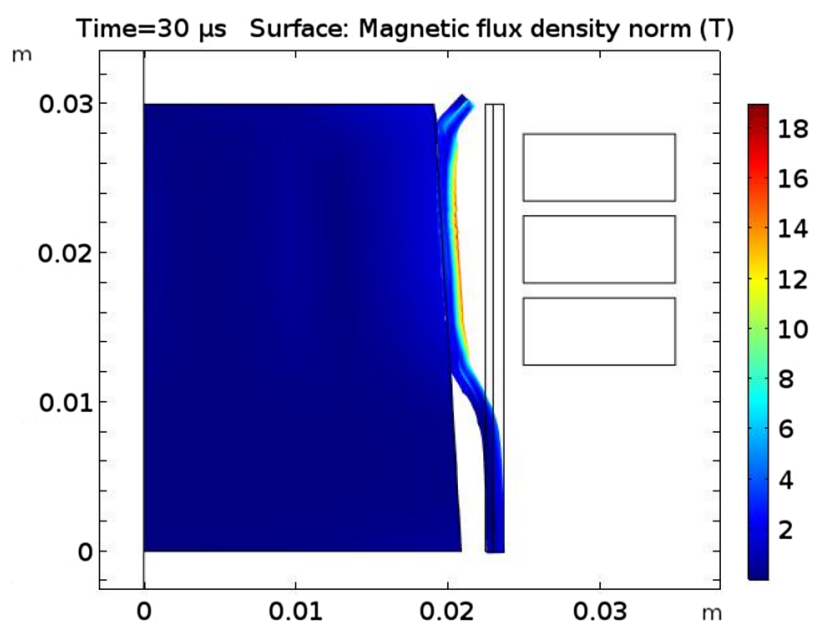

Figure 17. Contour diagram of magnetic flux after impact.

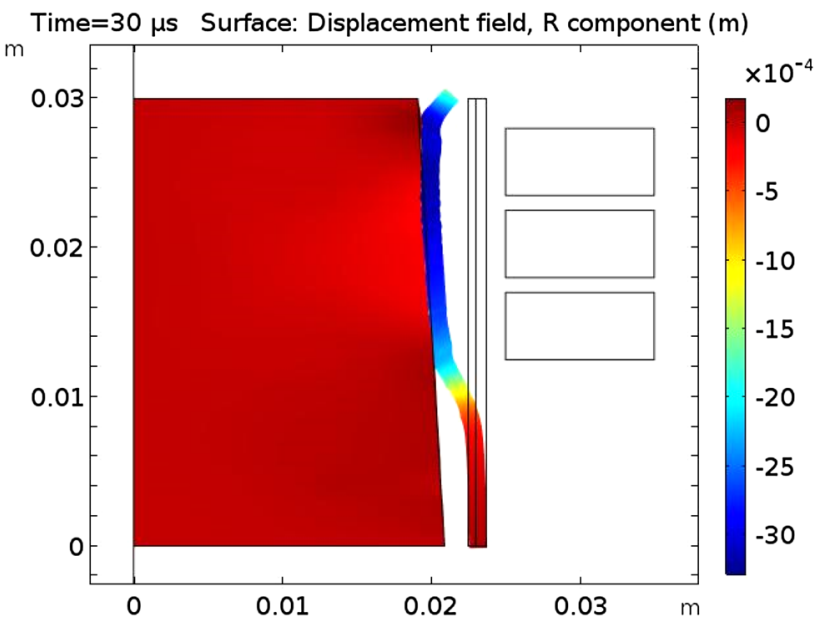

Figure 18. Contour diagram for flyer displacement.

The contour diagram of magnetic flux in figure 17 indicated magnetic flux density between 14-16 T. This is in complete agreement with the experimental magnetic flux calculated at $15 \mathrm{~T}$. The displacement of the flyer (figure 18) radially towards the target after the peak time of $20 \mu \mathrm{s}$ was recorded at $3 \mathrm{~mm}$, which is in agreement with the geometrical stand-off distance. In summary, a simulation study is able to establish the process parameters such as impact velocity, magnetic flux and displacement of the flyer in the magnetic field.

\section{Conclusion}

Experiment and simulation studies on EMW of mild steel1018 carbon steel and mild steel-stainless steel were carried out at $17 \mathrm{kV}$ and the following conclusions are drawn:

(1) The metallurgical bond was obtained for both mild steel-1018 carbon steel and mild steel-stainless steel. 
(2) The mild steel-1018 carbon steel interface indicated a complete merger of the interface without any demarcation, whereas mild steel-stainless steel indicated the presence of a melt zone of $3 \mu \mathrm{m}$ at the interface.

(3) The mild steel-1018 carbon steel interface was associated with severe plastic deformation with twinning, whereas mild steel-stainless steel was associated with diffusion of the major chemical elements including chromium and carbon in the interface region.

(4) Microhardness indicated a slight increase in the hardness value at the interface typical of EMW.

(5) The maximum peel force for the separation of the flyer and target was found at $1178 \mathrm{~N} \mathrm{~mm}^{-1}$ for mild steelstainless steel. Low-peel strength of $416 \mathrm{~N} \mathrm{~mm}^{-1}$ for mild steel-1018 carbon steel was justified by the presence of pitting at the interface.

(6) Simulation studies were in agreement with the experimental parameters such as impact velocity, magnetic flux and displacement, thus indicating that the simulation study is useful in setting the voltage needed for experiment.

\section{Acknowledgements}

The authors gratefully acknowledge the authorities of APPD, Bhabha Atomic Research Centre (BARC), for giving permission to conduct the experiment. The authors also acknowledge the support extended while conducting the experiments by the EMM team of PPSS, APPD at BARC, Mumbai.

\section{References}

[1] Shanthala K and Sreenivasa T N 2016 Front. Mech. Eng. 11 363

[2] Kapil A and Sharma A 2015 J. Cleaner Prod. 10035

[3] Shanthala K, Sreenivasa T N, Choudhury H, Dond S and Sharma A 2018 J. Mech. Sci. Technol. 321725

[4] Shribman V 2008 Magnetic pulse welding for dissimilar and similar materials, 3rd International conference on high speed forming - 2008 (ICHSF 2008) in Dortmund

[5] Marya M and Marya S 2004 Sci. Technol. Weld. Joining 9541

[6] Aizawa T, Kashani M and Okagawa K 2007 Weld. Joint 86119

[7] Kore S D, Imbert J, Worswick M J and Zhou Y 2009 Sci. Technol. Weld. Joining 14549

[8] Marya M, Marya S and Priem D 2005 Weld. World 4974

[9] Stern A and Aizenshtein M 2002 Sci. Technol. Weld. Joining 7 339

[10] Ghosh P, Patra S, Chattterjee S and Shome M 2018 J. Mater. Process. Technol. 25425

[11] Kacar R and Acarer M 2003 Mater. Sci. Eng. A 363290

[12] Kacar R and Acarer M 2004 J. Mater. Process. Technol. 152 91

[13] Ehsan Z and Liaghat G 2012 J. Mater. Sci. 47685

[14] Kumar S, Kulkarni M R, Saroj P C, Mittal K C and Gantayet L M 2013 Metallurgical and mechanical testing of electromagnetically welded copper and iron sample Asia Pacific conference on non-distructive testing (14th APCNDT) Mumbai, India, November 18-22 (APCNDT 2013) 